\title{
Development of a Compact Plasma Sterilization Device for Contact Lenses
}

\author{
Takehiko Sato, ${ }^{\mathrm{a}, *}$ Kazuki Okazaki, ${ }^{\mathrm{a}, \mathrm{b}}$ Tomoki Nakajima, ${ }^{a}$ Shigeru Fujimura, ${ }^{\mathrm{c}}$ \& \\ Tatsuyuki Nakatanid \\ alnstitute of Fluid Science, Tohoku University, Sendai, Japan; ' $G$ raduate School of Engineering, \\ Tohoku University, Sendai, Japan; ${ }^{\mathrm{C} T o h o k u ~ M e d i c a l ~ a n d ~ P h a r m a c e u t i c a l ~ U n i v e r s i t y, ~ S e n d a i, ~}$ \\ Japan; 'Okayama University of Science, Okayama, Japan
}

*Address all correspondence to: Takehiko Sato, Institute of Fluid Science, Tohoku University, 2-1-1 Katahira, Aoba-ku, Sendai 980-8577, Japan; Tel./Fax: +81-22-217-5320, E-mail: takehiko.sato.d7@tohoku.ac.jp

\begin{abstract}
In this study, our goal was to develop a contact lens sterilization device using non-thermal plasma. Three types of sterilization devices, a plasma-container-separated type (Ver. 1), a screw electrode type (Ver. 2), and a plasma actuator type (Ver. 3), were constructed and the electrical, chemical, and flow characteristics were investigated. Ver. 2 and Ver. 3 showed a good sterilization performance. The sterilization time was 2 minutes in air for both Ver. 2 and Ver. 3. In water, sterilization times were 30 minutes for Ver. 2 and 25 minutes for Ver. 3, because the chemical reactive species generated by these two devices were transported by the gas and water flows in the contact lens case. The effect of $\mathrm{pH}$ was also investigated, and we found that the low $\mathrm{pH}$ value with other reactive species such as ozone were important for sterilization. Finally, we propose a safe, small, and low power consumption device with high contact lens sterilization performance using plasma.
\end{abstract}

KEY WORDS: chemical transport, plasma-induced flow, water, low voltage

\section{INTRODUCTION}

The global market for contact lenses is a promising and growing market among the medical devices. ${ }^{1}$ In Japan, more than 15 million people use contact lenses and about $10 \%$ of the overall population is expected to use them. However, it is reported that about $7 \%$ to $10 \%$ of users experience eye damage. ${ }^{2}$

When contact lenses arrived in stores in 1972, the Ministry of Health, Labour and Welfare at that time required us to sterilize soft contact lenses (SCL) by boiling in normal saline solution. However, many users did not sterilize them every day, and we had some problems such as degradation of the materials or protein fixation by heating. Therefore, cold sterilization by chemicals such as thimerosal, chlorhexidine, or benzalkonium chloride were developed. The hydrogen peroxide system was also developed. But any chemicals or system could not kill Acanthamoeba completely, although the effectiveness against five types of experimental bacteria was properly validated. ${ }^{3}$ Also, the hydrogen peroxide system will cause eye damage without neutralization. Then a cold antiseptic solution called multipurpose solvent (MPS) was developed, which can be used for cleaning, rinsing, sterilizing, and preserving. MPS was called the thirdgeneration cold antiseptic solution and has been sold in Japan since 1996. Currently, it 
is dominating the market because it contains preservatives and does not need neutralization. However, the sterilizing effect is insufficient against various microorganisms such as Acanthamoeba, which causes loss of vision and strong eye pain, and is the main cause of intractable corneal disease, which may result in blindness. We need to scrub the lenses to remove these microorganisms completely.

On the other hand, an ozone disinfection method and other nonchemical methods were also developed. Ozone disinfection was effective against fungi and showed an excellent sterilizing effect, but it is not yet in practical use because of its toxicity to human tissues. Also, ultraviolet or electromagnetic ray methods have been developed but are not in general use.

As just described, the actual situation of SCL sterilization is that it has no choice but to rely on the thorough education and instructions for their use. We are in a difficult situation to improve the safety and convenience dramatically in the future. If we could develop innovative sterilization and disinfection methods that substantially improve efficiency, cleaning time, and cost, we will be able to prevent serious eye damage. Furthermore, if the special cleaning solution becomes unnecessary, use of contact lenses will be more convenient and alternative sterilization methods will be required.

Low temperature plasma is a novel sterilization method to solve the disadvantages just mentioned. Because plasma can be used to generate chemically reactive species and flow, it has been recently used for a wide range of medical applications, such as sterilization, surface modification for medical equipment, and blood coagulation. ${ }^{4-10}$

In this study, we will consider steps to overcome tasks of convenience and sterilization efficacy of current contact lens antiseptic solutions, using characteristics of excellent convenience and sterilization efficacy of plasma, which can quickly sterilize contact lenses with only electricity and water. Therefore, this study focuses on the development of sterilization devices that can sterilize the lenses with plasma and tap water. For the development of this device, we will use dielectric barrier discharge (DBD), which can generate plasma at low temperature.

\section{EXPERIMENTAL METHODS}

The schematic of the experimental setup is shown in the Fig. 1. The power source (Lika, LM-12500A-3: $80 \times 30 \times 16 \mathrm{~mm}$ ) supplied a voltage of $\mathrm{AC} \pm 3.1 \mathrm{kV}$ with the frequency of $27 \mathrm{kHz}$. The electrodes were connected to the contact lens case, and the case was filled with the plasma generation gas. We considered three structures of the electrodes, Ver. 1, Ver. 2, and Ver. 3, which are shown in Fig. 1. The characteristics of the structures are described next.

In Ver. 1, the plasma was generated by dielectric barrier discharge (DBD) between the aluminum tape electrode, which was attached to the outside wall of the silica glass tube, and the stainless steel screw electrode, which was placed inside the silica glass tube. The inside diameter of the glass tube was $8.5 \mathrm{~mm}$, the outside diameter was 10 $\mathrm{mm}$, and the length was $10 \mathrm{~mm}$. The aluminum tape was $5 \mathrm{~mm}$ in diameter. The stainless 

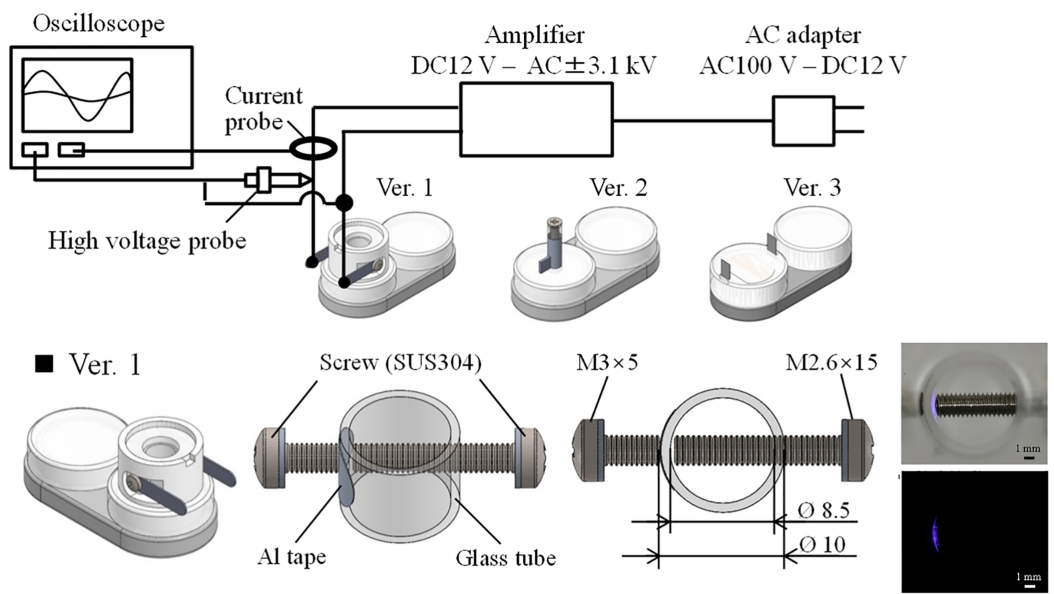

Ver. 2
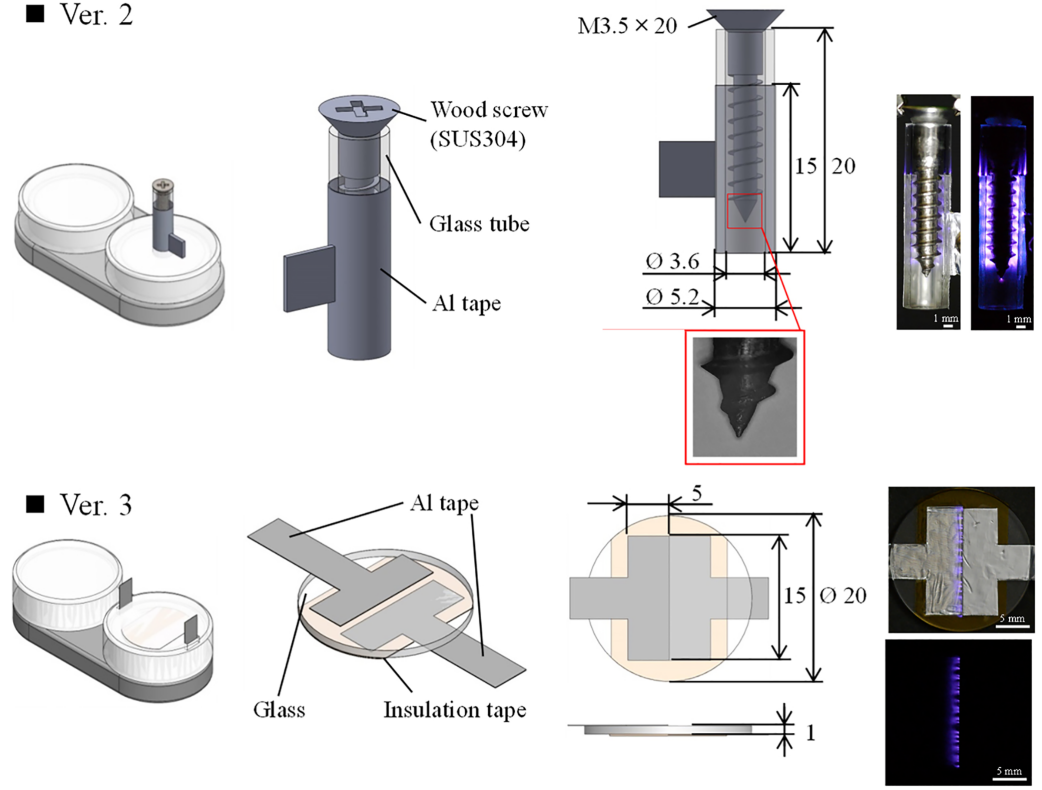

FIG. 1: Schematic of the experimental setup, the details of electrode configurations, and the plasma emission photographs

steel screw outside of the glass tube was $3 \mathrm{~mm}$ in diameter with $5 \mathrm{~mm}$ in length. The stainless steel screw inside of the glass tube was $2.6 \mathrm{~mm}$ in diameter with $15 \mathrm{~mm}$ in length. Our goal was to generate ozone with this device.

In Ver. 2, the stainless steel screw electrode was passed through the center of the glass tube, which was wrapped with the aluminum tape electrode, and the plasma was generated by the DBD inside the glass tube. ${ }^{11}$ The silica glass tube had an outside diameter of $5.2 \mathrm{~mm}$, an inside diameter of $3.6 \mathrm{~mm}$, and a length of $20 \mathrm{~mm}$. The stainless steel screw was $3.5 \mathrm{~mm}$ in diameter with $5 \mathrm{~mm}$ in length. The aluminum tape was $15 \mathrm{~mm}$ in 
length. The radius of curvature for the tip of the stainless steel screw was $100 \mu \mathrm{m}$. We aimed for the generation of nitrogen oxide and flow field.

In Ver. 3, the electrodes were placed in a staggered arrangement on both sides of the dielectric body, and it generated plasma and induced flow when a high-frequency alternating high voltage was applied. We attached this electrode to the inside of the cover of the contact lens case to reduce its size and to improve the sterilization efficacy by promoting transport of chemical species by induced flow. The aluminum tapes were attached to both sides of the glass disk in a staggered arrangement. The insulating tape was attached to one side because it discharged only at one side. The glass disk was 20 $\mathrm{mm}$ in diameter and $1 \mathrm{~mm}$ in thickness. The aluminum tape electrode was $15 \mathrm{~mm}$ long. We aimed for the generation of ozone and flow field.

The waveforms of the discharge current and the applied voltage were measured with an oscilloscope (LeCroy WaveSurfer, 104MXs), the current probe (Magnelab, CTD1.0-BNC), and the high voltage probe (Iwatsu, HV-P30). The discharge power was obtained by the Lissajous figure using the $220 \mathrm{pF}$ capacitor at the side of the grounding electrode, and the voltage between the capacitors was measured by using the voltage probe (LeCroy, PPE6 kV). The consumption power of the whole device was measured by the watt-hour meter (System Artware, SHW3A). In all cases, atmospheric air was used to generate plasma.

A digital camera (Nikon, D4) was used to document plasma emission. Spectrum analysis was measured with a multichannel spectroscope (Hamamatsu, PMA-12C10029). The vibrational temperature $\left(T_{\text {vib }}\right)$ and the rotational temperature $\left(T_{\text {rot }}\right)$ of $\mathrm{N}_{2}$ were obtained by fitting the observed spectrum of the second positive system (SPS) and the spectrum obtained by calculation. We used the analysis software provided at the Akatsuka lab, Laboratory for Advanced Nuclear Energy, Tokyo Institute of Technology. ${ }^{12-15}$

The concentration changes of ozone and the nitrogen oxide species with respect to the discharge time were measured with a gas detector tube (Gastec, Model-GV100). The changes in concentration of hydrogen peroxide, ozone, nitrous acid, and nitric acid relative to the discharge time were measured with a digital water quality meter (Kyoritsu Chemical-Check Lab, DPT-MT) and the Pack Test. The $\mathrm{pH}$ value was measured with a $\mathrm{pH}$ meter (ASONE, twin $\mathrm{pH}$ ). All measurements were performed in triplicate for each analysis, and the average and standard deviation were determined.

The Schlieren method was used for the visualization of the flow field. Methyl red solution (Wako Pure Chemical Corporation, 136-14125) (1 mL) was used to visualize the flow of the underwater chemical species. The solution consisted of $950 \mu \mathrm{L}$ pure water and $50 \mu \mathrm{L}$ methyl red solution in the silica glass cell. The inside of the glass cell was 20 $\mathrm{mm}$ wide, $10 \mathrm{~mm}$ deep, and $8 \mathrm{~mm}$ high, and the wall was $2 \mathrm{~mm}$ thick.

The biological indicator (BI) (3M Healthcare, Attest 1291), which uses spore bacteria of Geobacillus stearothermophilus (ATCC 7953), was used for the sterilization validation. It ensures a 5-log reduction of bacteria. The auto reader (3M Healthcare, Attest 290, 290G) was used for the sterilization decision of the BI. For the validation procedure, a spore-coated paper of the BI was placed inside the contact lens case with $2 \mathrm{~mL}$ water, and the plasma discharge was performed. After discharge, the paper was 
returned to the BI container, and the auto reader was used to determine the extent of sterilization. In this study, the sterilization test was conducted in triplicate. We judged that the sterilization decision was obtained when we obtained the sterilization completion decision all three times.

\section{EXPERIMENTAL RESULTS}

\section{A. Characteristics of Sterilization}

The result of the sterilization performance test is shown in the Table 1. Here, "+" indicates sterilization failed, and "-" means sterilization was successful. The sterilization in air in Ver. 1 was completed in 30 minutes, but in water, sterilization was not completed even after 3 hours. The sterilization time in Ver. 2 was 3 minutes in air and 30 minutes in water. The sterilization time in Ver. 3 was 3 minutes in air and 25 minutes in water. To clarify the reason for these results, the electrical, chemical, and flow characteristics were measured.

\section{B. Electrical Characteristics}

The voltage and current waveforms of Ver. 1, Ver. 2, and Ver. 3 are shown in Fig. 2. In each device, the voltage was $\pm 3.1 \mathrm{kV}$ in a sinusoidal wave with a frequency of $27 \mathrm{kHz}$. The generations of 20 to $50 \mathrm{~mA}$ displacement current and pulsed electrical current less than $20 \mathrm{~mA}$ were measured at the rise and fall of the voltage, which indicates that plasma was generated. The number of times of the pulsed current was only several times in one cycle in Ver. 1, but many pulses were generated in Ver. 2 and Ver. 3. The discharge power

TABLE 1: Sterilization results in the air and water in the cases of Ver. 1, Ver. 2, and Ver. 3

\begin{tabular}{|c|c|c|c|c|c|c|}
\hline \multicolumn{7}{|c|}{ Air } \\
\hline & & \multicolumn{5}{|c|}{ Discharge time (min) } \\
\hline & & 2 & 3 & 10 & 20 & 30 \\
\hline \multirow[t]{3}{*}{ Result of sterilization } & Ver. 1 & & & + & -++ & --- \\
\hline & Ver. 2 & +-- & --- & -- & - & - \\
\hline & Ver. 3 & -++ & --- & - & & - \\
\hline \multicolumn{7}{|c|}{ Water } \\
\hline & & \multicolumn{5}{|c|}{ Discharge time (min) } \\
\hline & & 20 & 25 & 30 & 60 & 180 \\
\hline \multirow[t]{3}{*}{ Result of sterilization } & \begin{tabular}{|l|} 
Ver. 1 \\
\end{tabular} & & & & + & + \\
\hline & Ver. 2 & +++ & ++- & --- & - & \\
\hline & Ver. 3 & -+- & --- & - & - & \\
\hline
\end{tabular}

+ , not sterilized; -, sterilized.

Volume 11, Issue 1, 2021 

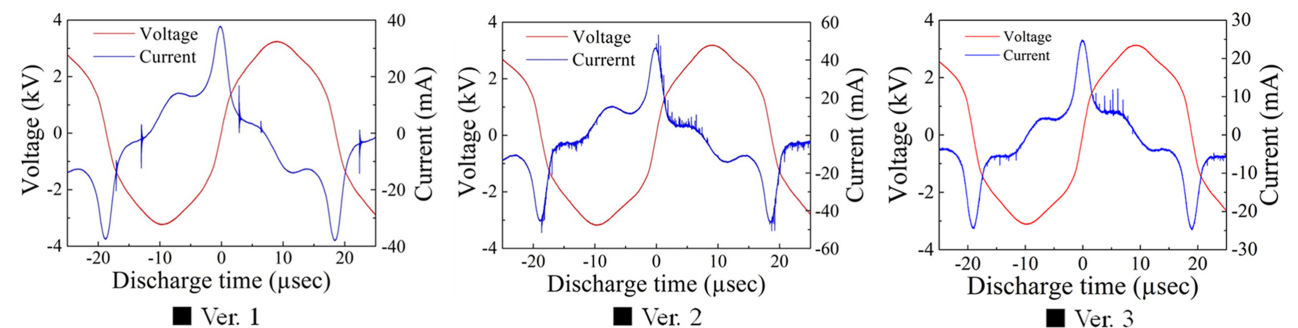

FIG. 2: Waveforms of the applied voltage and discharge current in the cases of Ver. 1, Ver. 2, and Ver. 3

was $0.23 \mathrm{~W}$ in Ver. $1,1.0 \mathrm{~W}$ in Ver. 2 , and $0.30 \mathrm{~W}$ in Ver. 3 . The total power consumption including the power source was $2.0 \mathrm{~W}$ in Ver. 1, $3.5 \mathrm{~W}$ in Ver. 2, 2.0 W in Ver. 3. From these results, Ver. 2 had the larger discharge power and power consumption because the Joule heating at the tip of the electrode or the current-concentrating point of the screw thread probably occurred.

\section{Chemical Characteristics}

The measurements of ozone and nitrogen oxide concentrations generated in air with respect to the discharge time of each device is shown in Fig. 3. In Ver. 1, the ozone concentration in air linearly increased with discharge, and the highest concentration of ozone of $1,900 \mathrm{ppm}$ in air was detected at the sterilization completion time of $30 \mathrm{~min}$ utes. However, the concentration of nitrogen oxide in air was less than $0.04 \mathrm{ppm}$, which is the lower limit of the detection tube. In Ver. 2, the concentration of nitrogen oxide in air increased with discharge time, and the highest concentration of nitrogen oxide of $4,700 \mathrm{ppm}$ in air was detected at a sterilization completion time of 3 minutes. On the other hand, the concentration of ozone in air was less than 4 ppm, which is the lower limit of the detection tube. In Ver. 3, the concentration of ozone in air increased with discharge time, and the highest concentration ozone of 2,100 ppm was detected at the
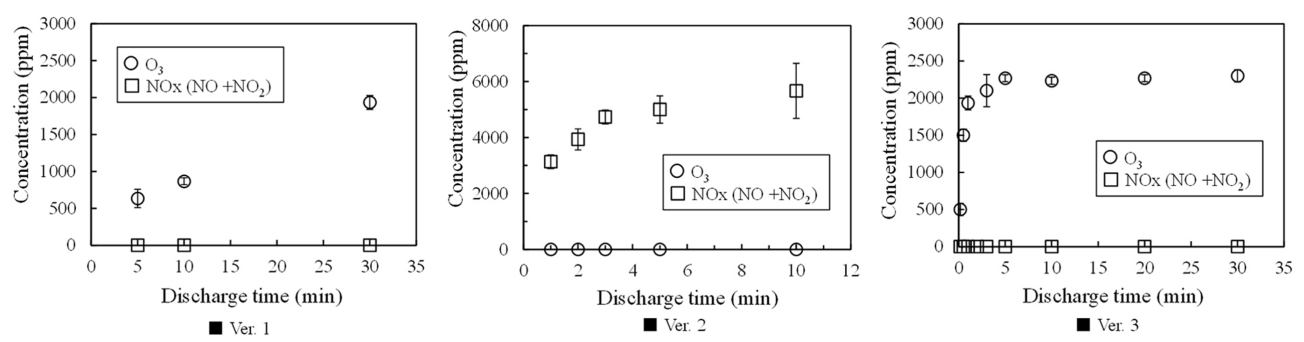

FIG. 3: Concentrations of $\mathrm{O}_{3}$ and $\mathrm{NO}_{\mathrm{x}}\left(\mathrm{NO}+\mathrm{NO}_{2}\right)$ in gas phase versus increasing discharge time in the cases of Ver. 1, Ver. 2, and Ver. 3 
sterilization completion time of 3 minutes. On the other hand, the concentration of nitrogen oxide in air was less than $0.04 \mathrm{ppm}$, which is the lower limit of the detection tube. From these results, Ver. 3 had the higher rate of ozone generation and reached a higher concentration, although there was no change in the discharge power in Ver. 1 and Ver. 3 . The decrease of ozone concentration in Ver. 2 was probably caused by the heating at the tip of screw needle due to higher electric field, because ozone readily decomposes at higher temperature and changed to nitrogen oxides in the air. The rotation temperatures of $\mathrm{N}_{2}$ were $0.036 \mathrm{eV}$ for Ver. $1,0.042 \mathrm{eV}$ for Ver. 2, and $0.036 \mathrm{eV}$ for Ver.3. ${ }^{12-16}$ This results also shows that the temperature of Ver. 2 is higher than other cases.

Then we compared the concentration of the chemical species generated in water in Ver. 2 and Ver. 3. The dissolved oxygen concentrations of $\mathrm{H}_{2} \mathrm{O}_{2}, \mathrm{O}_{3}, \mathrm{HNO}_{2}$, and $\mathrm{HNO}_{3}$ that were dissolved in pure water with respect to the discharge time of Ver. 2 and Ver. 3 are shown in Fig. 4. In Ver. 2, the highest concentration of nitric acid of $600 \mathrm{mg} / \mathrm{L}$ was detected at a sterilization time of 30 minutes. The concentration of $\mathrm{O}_{3}$ increased to 9 $\mathrm{mg} / \mathrm{L}$ in 15 minutes, but decreased to $2.5 \mathrm{mg} / \mathrm{L}$ in 30 minutes. In Ver. 3, the concentration of each chemical species linearly increased with discharge time. The concentration of nitric acid of $100 \mathrm{mg} / \mathrm{L}$ was detected at a sterilization completion time of 25 minutes. This concentration was much lower than Ver. 2. Also, the concentration of $\mathrm{O}_{3}$ increased with the discharge time, and we determined that it reached $10 \mathrm{mg} / \mathrm{L}$ in 25 minutes. Therefore, the sterilization time in water decreased because Ver. 3 can generate a higher concentration of $\mathrm{O}_{3}$. Also, the $\mathrm{pH}$ value decreased to 2.0 at the sterilization completion time of 30 minutes in Ver. 2, and decreased to 3.0 at a sterilization completion time of 25 minutes in Ver. 3.

\section{Flow and Temperature Characteristics}

Figure 5 shows the Schlieren images with and without plasma in Ver. 1, Ver. 2, and Ver. 3. The contrasting density is the change of the refractive index with temperature, and the heated air flow by plasma generation was visualized. In Ver. 1, the flow path was set up between the discharge container and the contact lens case, and it showed that the flow
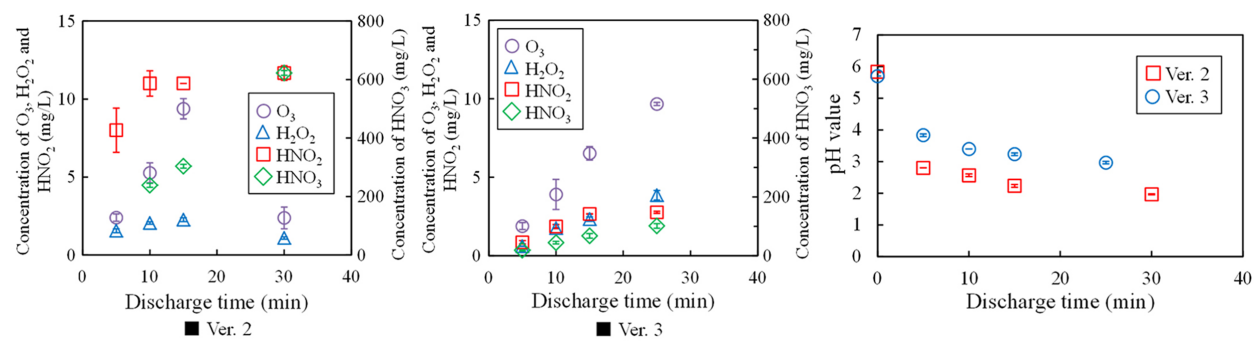

FIG. 4: Dissolved concentrations of $\mathrm{H}_{2} \mathrm{O}_{2}, \mathrm{O}_{3}, \mathrm{HNO}_{2}$, and $\mathrm{HNO}_{3}$ in the water versus discharge time in the cases of Ver. 2 (left) and Ver. 3 (middle). Temporal changes in $\mathrm{pH}$ value for pure water (right). 

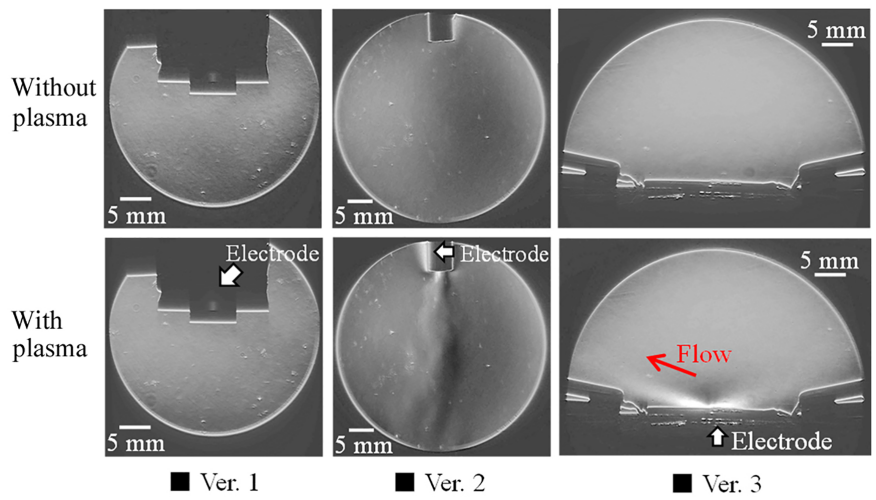

FIG. 5: Schlieren images of the plasma-induced flow in the cases of Ver. 1, Ver. 2, and Ver. 3. The upper row is without plasma, and the bottom row is with plasma.

generated in the discharge container was not flowing into the contact lens case. In Ver. 2, the air flow was generated toward the bottom from the electrode. It was confirmed that the air flow was not generated in the case without plasma. In Ver. 3, it was confirmed that the air flow was generated at about a 20 degree angle upward from the surface of the electrode in the presence of plasma. The reactive chemical species that was necessary for sterilization was transported by this flow. These results indicate that one of the reasons why the sterilization efficiency was low in Ver. 1 is that the chemical species generated by plasma was not transported efficiently. Also, visualization of the change of color of the methyl red solution indicated that the air flow generated above the water induces the underwater flow, and it transported the chemical species dissolved from the surface to the bottom of the container.

Figure 6 shows the temperature increased in (a) air and (b) water for Ver. 2 and Ver. 3. The temperature in the air increased approximately $16 \mathrm{~K}$ for Ver. 2 and approximately $6 \mathrm{~K}$ for Ver. 3 in 3 minutes. The temperature in the water increased approximately $11 \mathrm{~K}$ for Ver. 2 and approximately $5 \mathrm{~K}$ for Ver. 3 in 30 minutes. G. stearothermophilus spores
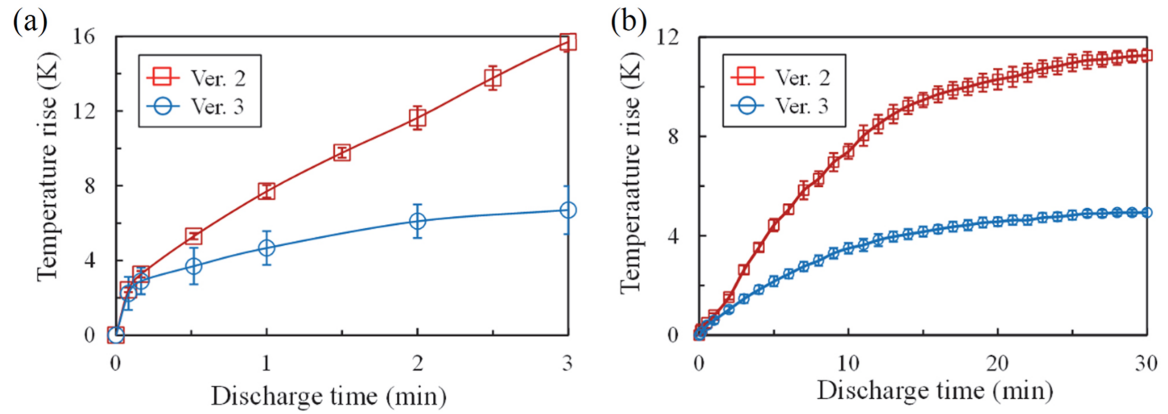

FIG. 6: Temperature rise in (a) air and (b) water for Ver. 2 and Ver. 3 
are not sterilized at this temperature increase because they are heat-resistant. Therefore, the sterilization was not caused by increased temperature.

\section{E. Influence of pH Value on Sterilization Efficiency}

Figure 4 shows that $\mathrm{pH}$ value decreased to 2.0 at the sterilization completion time of 30 minutes in Ver. 2, and it decreased to 3.0 at 25 minutes in Ver. 3. To verify the correlation between the decrease in $\mathrm{pH}$ and the sterilization efficiency, we considered the efficiency in the case where plasma processing was conducted while maintaining a neutral $\mathrm{pH}$ by using nitrous acid at the same concentration as plasma, water solution including nitric acid, and $\mathrm{pH}$ buffer solution. When we decrease only the $\mathrm{pH}$ without plasma processing, we generated nitrous acid solution, nitric acid solution, mixture of nitrous acid solution and nitric acid solution at the same concentration as the nitrous acid and the nitric acid that were detected in the sterilization completion time in the underwater chemical species analysis in Fig. 4. Then we exposed the BI paper to the $2,000 \mu \mathrm{L}$ solution in the contact lens case for the amount of time required for sterilization. Nitrous acid (Kanto Chemical Co., Inc., 28308-01) and nitric acid (Wako Pure Chemical Corp., 149-06845) were used to make solutions. In the experiment to maintain the neutral $\mathrm{pH}$, we processed for $30 \mathrm{~min}$ utes (Ver. 2) and 25 minutes (Ver. 3), which were the underwater sterilization completion times shown in Table 1, by using the $\mathrm{pH}$ buffer solution $(\mathrm{pH}=7.1)$ prepared by the potassium dihydrogen phosphate (Wako Pure Chemical Corp., 167-04241) and the sodium hydroxide solution (Wako Pure Chemical Corp., 196-02195). Here, the initial pH was 7.1.

The result of sterilization is shown in Table 2. (a) means that only the $\mathrm{pH}$ decreased, and (b) means that $\mathrm{pH}$ remained neutral. From (a), the sterilization was not completed in

TABLE 2: Sterilization results in the water in the cases of Ver. 2 and Ver. $3 \mathrm{pH}$ decrease associated with added $\mathrm{HNO}_{2}$ and $\mathrm{HNO}_{3}$ and $\mathrm{pH}$ constant associated with $\mathrm{pH}$ buffer

\begin{tabular}{|c|c|c|c|c|}
\hline \multicolumn{5}{|c|}{ pH decrease } \\
\hline & \multicolumn{2}{|c|}{ Ver. 2 (30 $\mathrm{min})$} & \multicolumn{2}{|c|}{ Ver. 3 (25 min) } \\
\hline & Sterilization results & pH & Sterilization results & pH \\
\hline Plasma & --- & 2.0 & --- & 3.0 \\
\hline $\mathrm{HNO}_{2}$ & +++ & 3.3 & +++ & 4.0 \\
\hline $\mathrm{HNO}_{3}$ & -+- & 2.0 & +++ & 2.7 \\
\hline $\mathrm{HNO}_{3} \& \mathrm{HNO}_{2}$ & --- & 2.0 & +++ & 2.7 \\
\hline \multicolumn{5}{|c|}{$\mathrm{pH}$ constant } \\
\hline & \multicolumn{2}{|c|}{ Ver. 2 (30 $\mathrm{min})$} & \multicolumn{2}{|c|}{ Ver. 3 (25 min) } \\
\hline & Sterilization results & pH & Sterilization results & pH \\
\hline Plasma & --- & 2.0 & --- & 3.0 \\
\hline Plasma with buffer & ++- & 6.9 & -++ & 7.0 \\
\hline
\end{tabular}

+ , not sterilized; -, sterilized.

Volume 11, Issue 1, 2021 
the nitrous acid solution in Ver. 2. In the case of the nitric acid solution, we could sterilize 2 samples out of 3 , but this resulted in incomplete sterilization as the comprehensive evaluation. With a mixture of nitrous acid solution and nitric acid solution, sterilization was completed. The sterilization mechanism of the spores is most likely caused by formation of a pit in the spore ${ }^{17}$ and the rupture of the cell membrane of vegetative cells. ${ }^{8}$ On the other hand, sterilized samples were not obtained in any condition in Ver. 3. These results indicate that the presence of nitric acid and the nitrous acid influences sterilization in Ver. 2, and the decrease in $\mathrm{pH}$ is one of the causes. On the other hand, effects of nitrous acid and the nitric acid was not confirmed in the sterilization in Ver. 3, and there may be other sterilization factors. Next, we can see from (b) that one sample out of three was sterilized in both Ver. 2 and Ver. 3 in the experiment to maintain neutral $\mathrm{pH}$ by using the $\mathrm{pH}$ buffer solution. These results indicate that a decrease in $\mathrm{pH}$ is required to complete sterilization within 30 minutes and 25 minutes in both Ver. 2 and Ver. 3, respectively. These results indicate that a decrease in $\mathrm{pH}^{18}$ and multiple effects of ozone or other chemicals are involved in the sterilization process.

\section{CONCLUSION}

We determined that the sterilization device developed in this study has a high sterilization performance, it is compact and safe, and it works on low power. High sterilization performance is obtained by inducing a flow field by plasma generation and promoting the transport of chemical species. The required sterilizing time could be decreased to 3 minutes in air and 25 minutes in water. We could drastically reduce the processing time because the required sterilization time of the existing contact lens antiseptic solution is 4 hours. It improved safety because the processing is conducted in the closed container, ozone decomposes naturally, and nitrogen oxide can be dissolved in the water in the container. Power consumption is only 2.0 to $3.5 \mathrm{~W}$ for the entire unit and $0.2 \mathrm{~W}$ to $1.0 \mathrm{~W}$ for the discharge point, so power minimization was realized. Ver. 3 particularly showed a high potential for practical applications because it reduces the generation of nitrogen oxide and can generate ozone stably.

\section{ACKNOWLEDGMENT}

This study was supported by Hirayama Manufacturing Corp.

\section{REFERENCES}

1. Global expansion of contact lens market. Functional materials. Global IBIS Editorial Office. 2011;31(1):63-6 (in Japanese).

2. Takahashi K, Utsumi Y, Todo K, Uotani J, Fukushita K, Takano S. Reports on aggregate results of the questionnaire on eye disorder by contact lenses. 2011 (in Japanese).

3. Disinfection performance of antiseptic for soft contact lenses against Acanthamoeba, based on factfinding survey of its use. National Consumer Affairs Center of Japan. 2009. (Press material: December $16,2009)$ (in Japanese). 
4. Moisan M, Barbeau J, Moreau S, Pelletier J, Tabrizian M, Yahia L. Low-temperature sterilization using gas plasmas: A review of the experiments and an analysis of the inactivation mechanisms. Int $\mathrm{J}$ Pharm. 2001;226(1-2):1-21.

5. Moreau M, Orange N, Feuilloley MGJ. Non-thermal plasma technologies: New tools for bio-decontamination. Biotechnol Adv. 2008;26(6):610-7.

6. Sato T, Miyahara T, Doi A, Ochiai S, Urayama T, Nakatani T. Sterilization mechanism for Escherichia coli by plasma flow at atmospheric pressure. Appl Phys Lett. 2006;89(7):073902.

7. Sato T, Fujioka K, Ramasamy R, Urayama T. Sterilization efficacy of a coaxial microwave plasma flow at atmospheric pressure. IEEE Trans Ind Appl. 2006;42(2):399-404.

8. Nakano Y, Fujimura S, Sato T, Kikuchi T, lchinose M, Watanabe A. Sterilization method using plasma discharge against biofilm producing Pseudomonas aeruginosa on surface of contact lens. J Med Biol Eng. 2015;35:626-33.

9. Muramatsu K, Sato T, Nakajima T, Nagasawa T, Nakatani T, Shigeru Fujimura S. Sterilization in liquids by air plasma under intermittent discharge. Mech Eng J. 2020;7(1):19-00431.

10. Wu MC, Uehara S, Wu JS, Xiao YC, Nakajima T, Sato T. Dissolution enhancement of reactive chemical species by plasma-activated microbubbles jet in water. J Phys D: Appl Phys. 2020;53:485201.

11. Okazaki K, Sato T, Oshitani H, Okamoto M, Nakajima T, Fujimura S. Development of small sterilization device using low temperature plasma flow for inactivation of virus. Proc 15th Int Symp Adv Fluid Inf. 2015;81-2.

12. Yuji T, Suzaki Y, Yamawaki T, Sakaue H, Akatsuka H. Experimental study of temperatures of atmospheric-pressure nonequilibrium $\mathrm{Ar} / \mathrm{N}_{2}$ plasma jets and poly(ethylene terephtalate)-surface processing. Jpn J Appl Phys. 2007;46:2:795-8.

13. Sakamoto T, Matsuura H, Akatsuka H. Spectroscopic study on the vibrational populations of $\mathrm{N}_{2} \mathrm{C}^{3} \Pi$ and $B^{3} \Pi$ states in a microwave nitrogen discharge. J Phys D: Appl Phys. 2007;101(2):023307.

14. Sakamoto T, Matsuura $\mathrm{H}$, Akatsuka $\mathrm{H}$. Spectroscopic study on vibrational distribution of $\mathrm{N}_{2} \mathrm{C}^{3} \Pi$ and $B^{3} \Pi$ states in microwave nitrogen discharge. J Phys D: Appl Phys. 2006;45:10:7905-10.

15. Koike S, Sakamoto T, Kobari H, Matsuura H, Akatsuka H. Spectroscopic study on vibrational nonequilibrium of a microwave discharge nitrogen plasma. Jpn J Appl Phys. 2004;43(8):5550-7.

16. Sato T, Furuya O, Ikeda K, Nakatani T. Generation and transportation mechanisms of chemically active species by dielectric barrier discharge in a tube for catheter sterilization. Plasma Process Polym. 2008;5(6):606-14.

17. Yoshino D, Nakamura K, Nakajima T, Sato T. Development of low-temperature sterilization device using atmospheric pressure air plasma with circulating flow. Mech Eng J. 2015;2:15-00187.

18. Ikawa S, Kitano K, Hamaguchi S. Effects of $\mathrm{pH}$ on bacterial inactivation in aqueous solutions due to lowtemperature atmospheric pressure plasma application. Plasma Process Polym. 2010;7(1):33-42.

Volume 11, Issue 1, 2021 
